\title{
PEDOPHILIA AS A LEGAL TERM (CRIMINAL PEDOPHILIA)
}

\author{
Vladislav V. Kolbasin \\ Krasnodar University of the Ministry of Internal Affairs of Russia, Krasnodar, Russian Federation
}

Introduction: in our opinion, special attention should be paid to the content of the terms "pedophilia" and "pedophile", which are often found in the analysis of the legal literature, the reports of government officials, on the Internet, as well as in the content of the normative legal acts regulating the responsibility for committing sexual crimes against the category of victims of interest to us. To date, none of the legal sources operating within the territory of the Russian Federation does not contain the interpretation of the above terms, which fully reveals the specifics of the form of sexual deviation we are studying. The purpose of the study is to analyze the legislation of the Russian Federation regulating the responsibility for the commission of a crime that encroaches on the sexual freedom and sexual integrity of minors and juveniles, by persons suffering from a disorder of sexual preference in the form of pedophilia, as well as the medical and psychological sources containing information about the sexual deviation we are studying, to form the concept of the terms "pedophilia" and "pedophile" in the legal sphere. Methods: the statistical method, the methods of induction, analysis and synthesis are used. Results: the paper considers various definitions of the terms "pedophilia", "pedophile". The paper analyzes the affiliation of the previously mentioned term with any branch of scientific knowledge. Conclusions: as a result of the conducted research, the author formulated the concepts of the terms "criminal pedophilia" and "criminal pedophile", whose use in the normative legal acts regulating the responsibility for committing crimes that infringe on the sexual freedom and sexual integrity of minors and juveniles, in our opinion, would contribute to the significant development of the system of combating sexual crime in relation to the category of citizens of interest to us.

Key words: pedophile, sexual crime, sexual integrity of minors, sexual freedom, pedophilia, juvenile, disorder of sexual preference, deviation.

Citation. Kolbasin V.V. Pedophilia as a Legal Term (Criminal Pedophilia). Legal Concept $=$ Pravovaya paradigma, 2021, vol. 20, no. 2, pp. 169-174. (in Russian). DOI: https://doi.org/10.15688/lc.jvolsu.2021.2.23

УДК 343.01

Дата поступления статьи: 11.02.2021

ББК 67.408

Дата принятия статьи: 01.03.2021

\section{ПЕДОФИЛИЯ КАК ЮРИДИЧЕСКИЙ ТЕРМИН (КРИМИНАЛЬНАЯ ПЕДОФИЛИЯ)}

\author{
Владислав Владимирович Колбасин \\ Краснодарский университет МВД России, г. Краснодар, Российская Федерация
}

\begin{abstract}
Аннотация. Введение. Исследуя насильственную сексуальную преступность в отношении малолетних и несовершеннолетних, особое внимание, на наш взгляд, следует уделить содержанию терминов «педофилия» и «педофил», часто встречающихся при анализе юридической литературы, докладов сотрудников государственных органов, в сети Интернет, а также в содержании нормативных правовых актов, регламентирующих ответственность за совершение половых преступлений в отношении интересующей нас категории поحิ терпевших. На сегодняшний день ни один из действующих на территории Российской Федерации правовых источников не содержит трактовки указанных терминов, в полной мере раскрывающей специфику исследуемой нами формы сексуальной девиации. Целью настоящего исследования является анализ законодательства Российской Федерации, регламентирующего ответственность за совершение преступления, посягающего на половую свободу и половую неприкосновенность малолетних и несовершеннолетних, лицами, страдающими расстройством сексуального предпочтения в форме педофилии, а также медицинских и психологических источников, содержащих в себе информацию об исследуемой нами сексуальной девиации, для
\end{abstract}




\section{ПРОТИВОДЕЙСТВИЕ ПРЕСТУПНОСТИ}

формирования понятия терминов «педофилия»и «педофил» в правовой сфере. Методы: использованы методы индукции, статистический, анализа и синтеза. Результаты: в рамках статьи рассмотрены различные дефиниции терминов «педофилия», «педофил». Осуществлен анализ принадлежности указанного ранее термина к какой-либо отрасли научного знания. Вывод: в результате проведенного исследования нами сформулированы авторские понятия терминов «криминальная педофилия» и «преступник-педофил», использование которых в нормативно-правовых актах, регламентирующих ответственность за совершение преступлений, посягающих на половую свободу и половую неприкосновенность малолетних и несовершеннолетних, на наш взгляд, способствовало бы значительному развитию системы противодействия сексуальной преступности в отношении интересующей нас категории граждан.

Ключевые слова: педофил, сексуальная преступность, половая неприкосновенность несовершеннолетних, половая свобода, педофилия, малолетний, расстройство сексуального предпочтения, девиация.

Цитирование. Колбасин В. В. Педофилия как юридический термин (криминальная педофилия) // Legal Concept $=$ Правовая парадигма. - 2021. - Т. 20, № 2. -C. 169-174. - DOI: https://doi.org/10.15688/lc.jvolsu.2021.2.23

\section{Введение}

Исследуя проблему противодействия сексуальным преступлениям, посягающим на половую неприкосновенность несовершеннолетних, в том числе - совершенных лицами, страдающими различного рода расстройствами сексуального предпочтения, мы сталкиваемся с тенденцией значительного увеличения количества случаев упоминания термина «педофилия» в юридической литературе, докладах сотрудников государственных органов, в сети Интернет, а также в содержании нормативных правовых актов.

В первую очередь, по нашему мнению, это связано с критическим уровнем половой преступности в современной России, жертвами которой становятся малолетние и несовершеннолетние лица. По словам генерал-майора полиции В.Б. Гайдова (заместителя начальника Главного управления по обеспечению охраны общественного порядка и координации взаимодействия с органами исполнительной власти субъектов РФ МВД России), в период с 2014 по 2019 г. число противоправных деяний, посягающих на половую неприкосновенность несовершеннолетних, выросло на 42 \%. В 2018 г. было зарегистрировано более 14 тысяч подобного рода деяний, пострадали 11 тысяч детей [5].

Кроме того, повышением уровня своей «популярности» термин «педофилия» обязан и сложившейся в настоящее время практике называть всех лиц, совершивших половое преступление в отношении интересующей нас категории потерпевших, педофилами. Безусловно, данное обстоятельство, чаще всего, объясняется отсутствием соответствующего образования, профессиональной квалификации либо элементарной неграмотностью лиц, допускающих подобного рода лексические ошибки.

Кто же из преступников, совершивших посягательство на половую неприкосновенность малолетних и несовершеннолетних, является педофилом? Каково значение педофилии в вопросах квалификации и расследования преступных деяний исследуемой нами категории, а также при назначении меры правового воздействия за их совершение? Что же такое «криминальная педофилия»?

Для того чтобы ответить на эти вопросы, по нашему мнению, необходимо осуществить правовое толкование термина «педофилия» («педофил»), ведь ни один из ныне действующих правовых источников в области регламентации ответственности за преступления, посягающие на половую свободу и половую неприкосновенность несовершеннолетних, не содержит трактовки, в полной мере раскрывающей специфику исследуемой нами формы сексуальной девиации.

\section{Дефиниция терминов «педофилия» и «педофил»в медицине и сексологии}

В связи с тем, что педофилия изначально понимается как психическое расстройство, являющееся предметом изучения медицины и сексологии, для более глубокого рассмотрения этого явления обратимся к материалам Международной статистической классификации болезней (МКБ-10). В соответствии с указанным источником, под педофилией понимается «сексуальная тяга к детям (мальчикам, 
девочкам или и к тем и другим), обычно препубертатного и раннего пубертатного периода» [8]. В специальной литературе отмечается, что для установления диагноза «педофилия» необходимо наличие у субъекта следующих признаков:

- присутствие всех общих признаков расстройств полового предпочтения [6];

- преобладающее или постоянное предпочтение половой активности с детьми (ребенком) препубертатного или раннего пубертатного возраста (в соответствии с понятием, данным в психологическом глоссарии, пубертатный период - это временной отрезок с 12 до 16 лет у девушек и с 13 до 17-18 лет у мальчиков, на котором происходит их половое созревание) [2];

- достижение индивидуумом, по меньшей мере, 16 лет при разнице в возрасте с объектом сексуального влечения не менее 5 лет ${ }^{1}$.

Таким образом, с медицинской точки зрения, страдающим педофилией (педофилом) может быть признан индивид, достигший 16-летнего возраста, на протяжении не менее 6 месяцев страдающий от периодически возникающих сексуальных фантазий, объектом которых выступает лицо препубертатного или раннего пубертатного периода, и (или) сексуального влечения к приведенной ранее категории несовершеннолетних граждан.

\section{Педофилия в юриспруденции}

Исследуя проблему противодействия преступлениям, посягающим на половую свободу и половую неприкосновенность малолетних и несовершеннолетних, совершенным лицами, страдающими исследуемой нами формой сексуальной девиации, особое внимание, на наш взгляд, следует уделить грамотному отграничению психопатологических и непатологических причин совершенного сексуального злоупотребления. В первую очередь это связано с тем, что не все граждане, совершившие половое преступление в отношении интересующей нас категории потерпевших, являются педофилами (то есть лицами, имеющими устойчивое доминирующее сексуальное влечением к детям), ведь противоправные деяния подобного характера нередко совершаются и по другим причинам. Например, вследствие утери возрастной дифференциации объекта, наступившей под влиянием интоксикационных воздействий (наркотического или алкогольного опьянения). По мнению И.С. Кона, «большинство совратителей - не педофилы, а обычные мужчины с нормальной психикой, женатые и имеющие детей». Характеризуя данную категорию насильственных сексуальных преступников, Игорь Семенович описывает их как «слабых, неуверенных в себе мужчин, которым трудно чувствовать себя на равных со взрослыми женщинами, даже с собственной женой», совершающих посягательство на половую неприкосновенность несовершеннолетних не из-за возбуждающей половой незрелости и половой незавершенности жертвы, а по причине ее беззащитности и слабости [7, с. 491].

Кроме того, стоит обратить внимание на то обстоятельство, что не все индивиды, страдающие интересующим нас расстройством сексуального предпочтения, когда-либо совершали или совершат половое преступление. Многие из них пытаются побороть возникающее половое влечение к детям или реализуют свои сексуальные потребности путем просмотра порнографических материалов, мастурбации или реальным общением с несовершеннолетними в виртуальной среде без сексуального контекста [3].

Анализируя нормативно-правовую базу Российской Федерации в области регламентации уголовной ответственности за преступления, посягающие на половую неприкосновенность несовершеннолетних, следует отметить, что термин «педофилия» встречается в ней довольно часто. Например, в соответствии с п. 4.1 ч. 4 ст. 79 УК РФ «Условно-досрочное освобождение от отбывания наказания» и п. «Д» ст. 97 УК РФ «Основания применения принудительных мер медицинского характера» педофилию относят к расстройствам сексуального предпочтения, не исключающим вменяемости [11], а в п 3.1 ст. 196 УПК РФ «Обязательное назначение судебной экспертизы» под педофилией понимается расстройство сексуального предпочтения [10]. При этом во всех приведенных случаях термин «педофилия» неразрывно связывают с совершением лицом старше 18 лет преступления против половой неприкосновенности несовер- 


\section{ПРОТИВОДЕЙСТВИЕ ПРЕСТУПНОСТИ}

шеннолетнего, не достигшего четырнадцатилетнего возраста. Между тем ответственность за совершение преступных деяний, предусмотренных ст. 131 УК РФ «Изнасилование» и ст. 132 УК РФ «Насильственные действия сексуального характера», в соответствии с ч. 2 ст. 20 УК РФ «Возраст, с которого наступает уголовная ответственность» наступает при достижении лицом четырнадцатилетнего возраста. Кроме того, опираясь на положения МКБ-10, педофилом можно считать лицо, достигшее 16-летнего возраста.

Содержание уголовно-правовых норм приводит нас к выводу, что в российском законодательстве ужесточение мер правового воздействия, а равно признаниелица страдающим педофилией, наблюдается лишь в отношении граждан, достигших на момент совершения преступления, посягающего на половую неприкосновенность малолетнего, возраста 18 лет, или совершеннолетия. На наш взгляд, данная ситуация явно не соответствует общей концепции противодействия насильственной половой преступности, жертвами которой становятся малолетние и несовершеннолетние лица. В частности, это связано с отсутствием возможности обеспечить достижение целей уголовного наказания, указанных в ч. 2 ст. 43 УК РФ «Понятие и цели наказания» - восстановление социальной справедливости, исправление осужденного и предупреждение новых преступлений подобного характера [11].

При этом стоит отметить, что число насильственных преступлений сексуального характера в отношении интересующей нас категории потерпевших со стороны несовершеннолетних в России с каждым годом растет. Анализируя «Доклад о деятельности Уполномоченного при Президенте Российской Федерации по правам ребенка за 2019 год» Анны Кузнецовой, мы видим, что число подобного рода деяний в период с 2017 по 2019 г. увеличилось на 45,4 \% [4, с. 53].

По нашему мнению, значительный рост, преступлений педофильного характера со стороны несовершеннолетних в первую очередь связан с глобальной информатизацией общества, а именно, влиянием на сознание индивида так называемой «сексуальной революции», все чаще и чаще пропагандируемой в сети Интернет, а также со снижением возраста пользователей социальных сетей и, как следствие, появившейся возможностью у интересующей нас категории граждан посещать неограниченное количество видеохостингов, сайтов, коммуникативных сообществ и других интернет-ресурсов, содержащих информацию порнографического характера, ознакомление с которой влечет к раннему (в некоторых случаях девиантному) половому созреванию. Стоит также обратить внимание на уровень виктимности рассматриваемого нами вида насильственной половой преступности. По мнению Ю.М. Антоняна, деяния исследуемой нами категории, совершенные несовершеннолетними, как правило, отличаются повышенным уровнем виктимности. В частности, это связано с нежеланием рассказывать о случившемся ни взрослым, ни своим ровесникам изза чувства стыда и боязни предания случившемуся всеобщей огласки, что впоследствии приводит к увеличению случаев повторного совершения сексуальных злоупотреблений, в том числе с привлечением к совершению аналогичных противоправных действий других асоциальных подростков [9, с. 184]. Кроме того, Юрий Миранович обратил внимание на особую опасность рассматриваемой нами категории преступлений, отметив, что одним из крайне негативных последствий полового контакта ребенка с лицом старше него (чаще гомосексуального) является дезориентация несовершеннолетнего потерпевшего в нормальном половом развитии, в дальнейшем, при взрослении, приводящая к совершению аналогичных противоправных деяний, с вовлечением других детей младше себя в подобного рода девиантные отношения [9, с. 20-21].

\section{Выводы}

Таким образом, говоря о принадлежности терминов «педофилия» и «педофил» к какой-либо отрасли научного знания, а также основываясь на толковании понятия «юридический термин» ${ }^{2}$, данного в Большом юридическом словаре [1], мы считаем возможным предположить, что «педофилия» может использоваться в качестве специально-технического юридического термина. Его лексическое значение в правовой сфере, на наш взгляд, должно выглядеть следующим образом. 
Криминальная педофилия - это не исключающее вменяемости расстройство сексуального предпочтения, выраженное в периодически возникающем сексуальном влечении и (или) сексуальной фантазии, объектом которых выступают лица препубертатного и раннего пубертатного возраста, побудившее индивида к совершению общественно опасного деяния, запрещенного уголовным законом под угрозой наказания.

Преступник-педофил - лицо, достигшее возраста 16 лет, на протяжении не менее 6 месяцев страдающее не исключающим вменяемости расстройством сексуального предпочтения, выраженным в устойчивом доминирующем сексуальном влечении к детям (мальчикам, девочкам или и к тем и другим) препубертатного и раннего пубертатного возраста, послужившим причиной совершения им уголовно наказуемого деяния.

При этом использование приведенных автором дефиниций в нормативно-правовых актах, регламентирующих ответственность за совершение преступлений, посягающих на половую свободу и половую неприкосновенность малолетних и несовершеннолетних, на наш взгляд, способствовало бы значительному развитию системы противодействия сексуальной преступности в отношении интересующей нас категории граждан, а также сокращению числа необоснованного и неграмотного употребления исследуемых нами терминов как в служебной деятельности, так и повседневной жизни.

\section{ПРИМЕЧАНИЯ}

${ }^{1}$ К общим критериям расстройств сексуального предпочтения в соответствии с МКБ-10 [8] относятся: периодически возникающее интенсивное сексуальное влечение и фантазии, включающие необычные предметы или поступки; индивидуум или поступает в соответствии с этими влечениями или испытывает значительный дистресс изза них; это предпочтение наблюдается минимум 6 месяцев.

2 Юридические термины - элемент юридической техники, словесные обозначения государственно-правовых понятий, с помощью которых выражается и закрепляется содержание нормативноправовых предписаний государства. Юридические термины можно классифицировать на три разно- видности: а) общезначимые термины (характеризуются тем, что они употребляются в обыденном смысле и понятны всем); б) специальные юридические термины, которые обладают особым правовым содержанием, например, необходимая оборона, исковая давность и т. п.; в) специально-технические термины - отражают область специальных знаний техники, экономики, медицины и т. д., например: ионизирующее излучение, трансгенные организмы.

\section{СПИСОК ЛИТЕРАТУРЫ}

1. Большой юридический словарь. - Электpoн. текстовые дан. - Режим доступа: https:// petroleks.ru/dictionaries/dict_big_law.php (дата обращения: 13.01.2021). - Загл. с экрана.

2. Глоссарий. Психологический словарь. Электрон. текстовые дан. - Режим доступа: http:// www.psychologies.ru/glossary/15/pubertatnyiyperiod/ (дата обращения: 12.01.2021). - Загл. с экрана.

3. Дерягин, Г. Б. Педофилия: пояснение для посторонних / Г. Б. Дерягин // Сексология и сексопатология. - 2006. - № 2. - С. 37-46. - Электрон. текстовые дан. - Режим доступа: https://web. archive.org/web/20090212223817/http://sudmednsmu.narod.ru/articles/pedo.html (дата обращения: 12.01.2021). - Загл. с экрана.

4. Доклад о деятельности Уполномоченного при Президенте Российской Федерации по правам ребенка в 2019 году / под ред. Р. Абдеева. - М. : Агилон, 2020. - 136 с. - Электрон. текстовые дан. Режим доступа: https://cdnimg.rg.ru/pril/article/189/ 23/87/DOKLAD_2019.pdf (дата обращения: 03.02.2021). - Загл. с экрана.

5. Интервью заместителя начальника Главного управления по обеспечению охраны общественного порядка и координации взаимодействия с органами исполнительной власти субъектов РФ генерал-майора полиции В.Б. Гайдова информационному агентству «ТАСС» от 15.10.2019 года. - Электрон. текстовые дан. - Режим доступа: https//tass.ru/ proisshestviya/7004001 (дата обращения: 12.01.2021). Загл. с экрана.

6. Классификация психических расстройств МКБ-10. Исследовательские диагностические критерии. - Электрон. текстовые дан. - Режим доступа: http://webmed.irkutsk.ru/doc/pdf/icd10ps.pdf (дата обращения: 12.01.2021). - Загл. с экрана.

7. Кон, И. С. Социологическая психология / И. С. Кон. - Электрон. текстовые дан. - Режим доступа: https://www.gumer.info/bibliotek_Buks/ Psihol/konsps/15.php (дата обращения: 14.01.2021). Загл. с экрана.

8. Международная классификация болезней (МКБ-10). - Электрон. текстовые дан. - Режим дос- 


\section{ПРОТИВОДЕЙСТВИЕ ПРЕСТУПНОСТИ}

тупа: https://mkb10.su/F65.4.html (дата обращения: 12.01.2021). - Загл. с экрана.

9. Педофилия: криминологический диагноз : монография / кол. авт. ; под ред. засл. деятеля науки России, д-ра юрид. наук, проф. Ю. М. Антоняна. М. : ВНИИ МВД Росссии, 2010. - 256 с.

10. Уголовно-процессуальный кодекс Российской Федерации от 18.12.2001 № 174-Ф3 (ред. от 08.12.2020) (с изм. и доп., вступ. в силу с 19.12.2020). Доступ из справ.-правовой системы «КонсультантПлюс».

11. Уголовный кодекс Российской Федерации от 13.06.1996 № 63-Ф3 (ред. от 30.12.2020). - Доступ из справ.-правовой системы «КонсультантПлюс».

\section{REFERENCES}

1. Bolshoy yuridicheskiy slovar [Big Legal Dictionary]. URL: https://petroleks.ru/dictionaries/ dict_big_law.php (accessed 13 January 2021).

2. Glossariy. Psikhologicheskiy slovar [Glossary. Psychological Dictionary]. URL: http:// www.psychologies.ru/glossary/15/pubertatnyiyperiod/ (accessed 12 January 2021).

3. Deryagin G.B. Pedofiliya: poyasneniye dlya postoronnikh [Pedophilia: An Explanation for Outsiders]. Seksologiya i seksopatologiya [Sexology and Sexopathology], 2006, no. 2, pp. 37-46. URL: https://web.archive.org/web/20090212223817/http:// sudmed-nsmu.narod.ru/articles/pedo.html (accessed 12 January 2021).

4. Abdeeva R., ed. Doklad o deyatelnosti Upolnomochennogo pri Prezidente Rossiyskoy Federatsii po pravam rebenka v 2019 godu [Report on the Activities of the Commissioner for the Rights of the Child under the President of the Russian Federation in 2019]. Moscow, Agilon, 2020. 136 p. URL: https://cdnimg.rg.ru/pril/article/189/23/ 87/DOKLAD_2019.pdf (accessed 3 February 2021).

5. Intervyu zamestitelya nachalnika Glavnogo upravleniya po obespecheniyu okhrany obshchestvennogo poryadka $i$ koordinatsii vzaimodeystviya s organami ispolnitelnoy vlasti subyektov RF general-mayora politsii V.B. Gaydova informatsionnomu agentstvu «TASS» ot 15.10.2019 goda [Interview with the Deputy Head of the Main Directorate for Ensuring the Protection of Public Order and Coordination of Interaction with the Executive Authorities of the Subjects of the Russian Federation Major General of Police V.B. Gaidov to the TASS News Agency dated 15.10.2019]. URL: https//tass.ru/ proisshestviya/7004001 (accessed 12 January 2021).

6. Klassifikatsiya psikhicheskikh rasstroystv MKB-10. Issledovatelskiye diagnosticheskiye kriterii [Classification of Mental Disorders ICD-10. Research Diagnostic Criteria]. URL: http://webmed.irkutsk.ru/ doc/pdf/icd10ps.pdf(accessed 12 January 2021).

7. Kon I.S. Sotsiologicheskaya psikhologiya [Sociological Psychology]. URL: https:/www.gumer. info/bibliotek_Buks/Psihol/konsps/15.php (accessed 14 January 2021).

8. Mezhdunarodnaya klassifikatsiya bolezney (MKB-10) [International Classification of Diseases (ICD-10)]. URL: https://mkb10.su/F65.4.html (accessed 12 January 2021).

9. Antonyan Yu.M., ed. Pedofiliya: kriminologicheskiy diagnoz: monografiya [Pedophilia: Criminological Diagnosis: Monograph]. Moscow, AllRussian Research Institute of the Ministry of Internal Affairs of Russia, 2010.256 p.

10. Ugolovno-protsessualnyy kodeks Rossiyskoy Federatsii ot 18.12.2001 № 174-FZ(red. ot 08.12.2020) (s izm. i dop., vstup. v silu s 19.12.2020) [The Criminal Procedure Code of the Russian Federation of 12/18/ 2001 No. 174-FZ (as Amended on 12/08/2020) (as Amended and Supplemented, Entered into Force on 12/ 19/2020)]. Access from Reference Legal System "KonsultantPlyus".

11. Ugolovnyy kodeks Rossiyskoy Federatsii ot 13.06.1996 № 63-FZ (red. ot 30.12.2020) [The Criminal Code of the Russian Federation of 13.06.1996 No. 63FZ (as revised on 30.12.2020)]. Access from Reference Legal System “KonsultantPlyus”.

\section{Information About the Author}

Vladislav V. Kolbasin, Associate Professor, Department of Criminal Law and Criminology, Krasnodar University of the Ministry of Internal Affairs of Russia, Yaroslavskaya St, 128, 350051 Krasnodar, Russian Federation, Kolbasin_vlad@mail.ru, https://orcid.org/0000-0002-2087-7374

\section{Информация об авторе}

Владислав Владимирович Колбасин, адъюнкт кафедры уголовного права и криминологии, Краснодарский университет МВД России, ул. Ярославская, 128, 350051 г. Краснодар, Российская Федерация, Kolbasin_vlad@mail.ru, https://orcid.org/0000-0002-2087-7374 